\title{
Lectotipificación de Cinco nombres en SENECio (AsteraceAe) de Argentina y Chile
}

\author{
MARCELO P. HERNÁNDEZ1 y DANIEL A. GIULIANO1
}

\begin{abstract}
Summary: Lectotypification of five names in Senecio (Asteraceae) from Argentina and Chile. Five names belonging to species of Senecio from Argentina and Chile are lectotypified: Senecio famatinensis Cabrera, Senecio madariagae Phil., Senecio niederleinii Cabrera, Senecio otaeguianus Phil. and Senecio triodon Phil.
\end{abstract}

Key words: Compositae, nomenclature, Senecio, Series Chilenses, Subseries Radiati.

Resumen: Se lectotipifican cinco nombres pertenecientes a especies de Senecio de Argentina y Chile: Senecio famatinensis Cabrera, Senecio madariagae Phil., Senecio niederleinii Cabrera, Senecio otaeguianus Phil. y Senecio triodon Phil.

Palabras clave: Compositae, nomenclatura, Senecio, Serie Chilenses, Subserie Radiati.

\section{INTRODUCCIÓN}

El género cosmopolita Senecio L. s.l., con aproximadamente 3000 especies, constituye una de las unidades sistemáticas más grandes dentro de las Angiospermas en general y de las Compuestas en particular. La mayor concentración de especies se halla en las regiones montañosas de América, África y Asia, mientras que está pobremente representado en las selvas ecuatoriales. Estudios moleculares recientes, han reducido el número de especies de Senecio a 1000-1200 (Pelser et al., 2007).

El propósito de este trabajo consiste en designar los lectotipos para cinco nombres de especies pertenecientes al género Senecio de Argentina y Chile, como una contribución nomenclatural a una próxima revisión taxonómica de la subserie Radiati (Cabrera) Cabrera \& S.E. Freire ubicada en la serie Chilenses DC. ex M.G. López, A.F. Wulff \& Xifreda.

\footnotetext{
${ }^{1}$ Área de Botánica, Departamento de Ciencias Biológicas, Facultad de Ciencias Agrarias y Forestales, Universidad Nacional de La Plata, calle 60 y 119, 1900 La Plata; mphciencia@yahoo.com
}

\section{Materiales y Métodos}

Se examinaron los protólogos de todos los nombres tipificados y se utilizaron fotografías e imágenes digitales de los especímenes tipos depositados en los Herbarios CORD y SGO (Thiers, 2012) y material del Herbario LP.

\section{Resultados}

Se lectotipificaron los siguientes nombres de especies:

Senecio famatinensis Cabrera, Notas Mus. La Plata, Bot. 1: 97. 1935. Lectotipo (designado aquí): Argentina. La Rioja, en la Sierra de Famatina, Cuesta del Tocino, 11-II-1879, Hieronymus \& Niederlein 684 (Foto! CORD).

El ejemplar holotipo depositado en B está probablemente destruido por lo que se designa como lectotipo el isotipo depositado en CORD. $\mathrm{Si}$ bien en LP existe un isotipo, el mismo es un fragmento pequeño y no permite una completa identificación de la especie.

Senecio madariagae Phil., Anales Mus. Nac. Chile, Bot. 8: 45. 1891. Lectotipo (designado aquí): 
Chile. Tarapacá, inter Amincha et Paroma, 25-II1885, F. Philippi s.n. (Foto! SGO 44483).

En el Herbario SGO existen dos cartulinas "SGO 44483" y "SGO 60740", en ambas se lee "Amincha et Paroma 25-II-1895". Se designa como lectotipo la cartulina "SGO 44483", por contener un espécimen que se corresponde mejor con el protólogo. Si bien Muñoz Pizarro (1960: 159) consigna "SGO 60739" como una de las cartulinas antes mencionadas, dicho ejemplar está claramente etiquetado "60740". El espécimen "SGO 60739" se excluye como perteneciente a la especie $S$. madariagae.

Senecio niederleinii Cabrera, Notas Mus. La Plata, Bot. 1: 104. 1935. Lectotipo (designado aquí): Argentina. La Rioja, en las cercanías del Potrerillo, lado del poniente del Cerro Famatina, 14-II-1879, Hieronymus \& Niederlein 692 (LP!).

El ejemplar holotipo depositado en B está probablemente destruido y se designa como lectotipo el isotipo depositado en LP.

Senecio otaeguianus Phil., Anales Univ. Chile 88: 246. 1894. Lectotipo (designado aquí): Chile. Valparaíso, Curauma, XI-1883, Philippi s.n. (Foto! SGO 60765).

Se han localizado tres cartulinas "SGO 60764", "SGO 60765" y "LP 63895" en donde se lee "Curauma, Nov. Oct? 1883". Se designa como lectotipo la cartulina "SGO 60765" por ser un espécimen que se corresponde mejor con el protólogo.

Existe además en LP y GH una fotografía del Field Museum of Natural History, "Nro. 15678", del ejemplar depositado en B actualmente destruido que se corresponde con el protólogo de $S$. otaeguianus Phil.

Senecio triodon Phil. Linnaea 28: 749. 1856. Lectotipo (designado aquí): Chile. Cordillera de Linares, I-1856, [Germain s.n.] (Foto! SGO 44542).

En el protólogo de Senecio triodon se nombran dos ejemplares, "in monte circa 5000 p. alto Cerro del doce de Febrero inter lacus Todos los Santos et Nahuel Huapi invenit Dr. Fr. Fonk; in Andibus depart. Linares orn Germain". En el Herbario SGO se encuentran tres cartulinas "SGO 60808", "SGO 60089" y "SGO 44542" que se corresponden con el protólogo de la especie. En la primera cartulina
"SGO 60808" se lee: "Nro 55. Cerro del Doce de Febrero a 5000 pies de altura cf. Nro 45". En la segunda cartulina "SGO 60089" se lee: Cordillera de Linares 1856. En la tercera cartulina "SGO 44542" se encuentran dos ejemplares, cada uno con su etiqueta; en uno se lee "Cordillera de Linares Enero 1856" y en el otro "Baños de Chillán, Janr. 1877". Este último espécimen no constituye un tipo dado que fue coleccionado posteriormente a la descripción de la especie. Se designa como lectotipo el ejemplar montado en la parte superior de la cartulina "SGO 44542" (Cordillera de Linares Enero 1856) por ser un espécimen que presenta hojas y un capítulo, el cual se corresponde mejor con el protólogo. Existe un isolectotipo en HAL (HAL 0112705).

\section{Agradecimientos}

Agradecemos a la Dra. Susana E. Freire y a dos revisores anónimos por la lectura crítica del manuscrito, asimismo a los curadores de los Herbarios CORD, LP y SGO por el suministro de imágenes digitales y material de herbario.

\section{Bibliografía}

MUÑOZ PIZARRO, C. 1960. Las especies de plantas descritas por R. A. Philippi en el siglo XIX. Ediciones de la Universidad de Chile, Santiago.

PELSER, P. B., J. W. KADEREIT \& L. E. WATSON. 2007. An ITS phylogeny of tribe Senecioneae (Asteraceae) and a new delimitation of Senecio L. Taxon 56: 1077-1104.

THIERS, B. 2012. Index Herbariorum: A global directory of public herbaria and associated staff. New York Botanical Garden's Virtual Herbarium. Disponible en: http://sweetgum.nybg.org/ih/ [Acceso: 3 Marzo 2013].

Recibido el 15 de marzo de 2013, aceptado el 3 de junio de 2013. 